\title{
GM1 locates to mature amyloid structures implicating a prominent role for glycolipid-protein interactions in Alzheimer pathology
}

Wojciech Michno ${ }^{1}$, Patrick Wehrli ${ }^{1}$, Henrik Zetterberg ${ }^{1-4}$, Kaj Blennow ${ }^{1,2}$ and Jörg Hanrieder 1,3,4,5

1) Department of Psychiatry and Neurochemistry, Sahlgrenska Academy at the University of Gothenburg, Mölndal, Sweden

2) Clinical Neurochemistry Laboratory, Sahlgrenska University Hospital, Mölndal, Sweden

3) Institute of Neurology, University College London, London, United Kingdom

4) UK Dementia Research Institute at UCL, London, United Kingdom

5) Department of Chemistry and Chemical Engineering, Chalmers University of Technology, Gothenburg, Sweden

* Contact:

Jörg Hanrieder, PhD

Dept. Psychiatry and Neurochemistry, Sahlgrenska Academy at the University of Gothenburg, Mölndal Hospital, House V, Biskopsbogatan 27, SE-43180 Mölndal, Sweden

jh@gu.se; +46313432377 


\section{Abstract:}

While the molecular mechanisms underlying Alzheimer's disease remain largely unknown, abnormal accumulation and deposition of beta amyloid $(A \beta)$ peptide into senile plaques has been identified as a critical pathological process driving disease progression. Over the last years, neuronal lipid species have been implicated in biological mechanisms underlying amyloid plaque pathology. While these processes comprise genetic features along with lipid signaling as well as direct chemical interaction of lipid species with $A \beta$ mono- and oligomers, more efforts are needed to spatially delineate the exact lipid $A \beta$ plaque interactions in the brain. Chemical imaging using mass spectrometry (MS) allows to probe the spatial distribution of lipid and peptide in complex biological tissues comprehensively and at high molecular specificity. As different imaging mass spectrometry (IMS) modalities provide comprehensive molecular and spatial information, we here describe a multimodal ToF SIMS- and MALDI-based IMS strategy for probing lipid and A $\beta$ peptide changes in a transgenic mouse model of $A D$. Both techniques identified a general AD-associated depletion of cortical sulfatides, while multimodal MALDI IMS revealed plaque specific lipid as well as $A \beta$ peptide isoforms in $A D$. In addition, MALDI IMS analysis revealed chemical features associated with morphological heterogeneity of individual $A \beta$ deposits, where altered (?) GM1 to GM2/GM3 ganglioside metabolism was observed in the diffuse periphery of the plaques but not in the center. This was accompanied by enrichment of the $A \beta 1-40$ arc peptide in the core of these deposits. Finally, in line with these observations, likely macrophage activity as revealed by the localization of arachidonic acid (AA) conjugated phosphatidylinositols $(\mathrm{PI})$ and their degradation product, lyso-phosphatidylinositols (LPI) to $A \beta$ plaque of the PI and LPI species to the plaque periphery was demonstrated. 


\section{Introduction}

Alzheimer's disease (AD) pathology is characterized by morphologically heterogeneous extracellular aggregates of amyloid- $\beta \quad(A \beta)$ as plaques together with aggregates of hyperphosphorylated tau protein in the form of neurofibrillary tangles and neuropil threads [1]. A wealth of studies implicates a critical role of $A \beta$ aggregation in early $A D$ pathogenesis, however the mechanisms behind $A \beta$ aggregation and toxicity in $A D$ are not completely understood [2-4]. $A \beta$ is produced from amyloid precursor protein (APP) by proteolytic processing via the $\beta$-site APPcleaving enzyme 1 (BACE1) and the $\gamma$-secretase complex and is degraded by a broad range of proteases. Its expression is particularly high in the brain. $A \beta$ exists as monomers, including at least 15 different isoforms, and is prone to form insoluble aggregates [5].

Neuronal lipids have been implicated in $A \beta$ pathogenesis by controlling trafficking and activity of membrane-bound proteins involved in $A \beta$ production, as well as by modulating the aggregation propensity of the peptide [6]. Indeed, several studies have reported that lipid mediated AD proteopathogenesis may also occur as a result of an abnormal protein-membrane interaction or altered lipid metabolism [7-9]. In detail, it has been suggested that neuronal glycolipids and cholesterol species coordinate $A \beta$ through electrostatic interactions and induce its conformational plasticity leading to oligomerization [10]. Moreover, glycolipids and cholesterol are heavily enriched in neuronal membrane domains termed lipid rafts. The fact that lipid raft disruption was found to protect neurons from neurotoxic fibrils further highlights the relevance of these domains and their constituents [9]. Finally, the $\varepsilon 4$ variant of the apolipoprotein $\mathrm{E}(A P O E)$ gene that encodes the E4 isoform of apoE, a lipid transporter protein, was identified as the major genetic risk factor for sporadic AD [11]. Taken together, it is therefore apparent that aberrant lipid homeostasis is tightly linked to $A \beta$ pathogenesis in $A D$.

The neuropathology of autosomal dominant and sporadic forms of AD (ADAD and SAD, respectively) is similar with respect to protein accumulation. Therefore, transgenic animal models, 
in which ADAD-causative mutations promote formation and aggregation of $A \beta$ deposits, provide a mean to study amyloidogenesis in AD. In particular, the transgenic mice models of the Arctic (E693) and Swedish (KM670/671NL) mutations of amyloid precursor protein (APPArcSwe) display both an early-onset of the $A \beta$ plaques and an extensive proliferation of these neurotoxic inclusions, making it a well-suited model system to study the underlying chemistry of the plaques.

Probing of pathological changes, such as $A \beta$ peptide aggregation and neuronal lipid alterations requires advanced chemical imaging techniques. Here, imaging mass spectrometry (IMS) is a powerful approach that enables comprehensive analysis of spatial intensity distribution profiles of molecular species in biological tissue and single cells [12]. In contrast to common biological imaging techniques, imaging MS does not require any a priori knowledge of the potential target species and is not dependent on antibody or primer availability and specificity. IMS features high molecular specificity and allows multiplexed detection, localization, identification and quantification of hundreds of peptides, metabolites and lipids in situ [12-15]. The technique employs different probes to desorb and ionize intact molecular species directly from a biological sample, where the most prominent approaches include time of flight secondary ion mass spectrometry (ToF-SIMS) [15] and matrix assisted laser desorption/ionization (MALDI) [14]. These different IMS modalities are complementary, since they have various strengths and limitations with respect to spatial resolution and molecular information [15]. SIMS which employs an ion beam facilitates highresolution imaging $(<1 \mu \mathrm{m})$, and is well suited for analysis of elemental and other inorganic species as well as organic low molecular weight compounds $(\mathrm{m}<1000 \mathrm{Da})$ including metabolites and lipids [16]. MALDI on the other hand, is well suited for imaging large molecular species such as peptides and intact proteins at $10 \mu \mathrm{m}$ lateral resolution $[15,16]$.

In the present study, we employed SIMS- and MALDI-based IMS to probe the subcellular molecular events underlying the aggregation of the neurotoxic $A \beta$ deposits in brain tissue of transgenic mouse model of $A D$ based on the Arctic (E693G) and Swedish (K670N, M671L) mutations of human APP $\left(\operatorname{tg} A P P P_{\text {ArcSwe }}\right)$. Multivariate statistical analysis was used to interrogate the 
multimodal IMS data sets in order to outline the relevant anatomical features. Region-specific differences in A $\beta$ peptide pattern as detected by MALDI-IMS were than correlated with changes in lipid distribution as revealed by high-resolution ToF-SIMS analysis.

\section{Materials and methods}

\subsection{Chemicals and reagents}

All chemicals for matrix and solvent preparation were pro-analysis grade and obtained from Sigma-Aldrich (St. Louis, MO, USA). TissueTek optimal cutting temperature compound was purchased from Sakura Finetek (AJ Alphen aan den Rijn, The Netherlands). The $\mathrm{ddH}_{2} \mathrm{O}$ was obtained from a milliQ purification system (Millipore Corporation, Merck Millipore, Billerica, MA, USA).

\subsection{Animals and Tissue Collection}

Transgenic mice $\left(\operatorname{tg} A P P_{\text {ArcSwe }}\right)(n=3,3$ male), 18 months of age, were reared ad libitum at the animal facility at Uppsala University under a 12/12-hlight/dark cycle[17]. The animals were anesthetized with isofluran and killed by decapitation. The brains were dissected quickly with 3 min postmortem delay and snap frozen on liquid nitrogen. All animal procedures were approved by an ethical committee and performed in compliance with national and local animal care and use guidelines (DNr \#C17/14 at Uppsala University).

Frozen tissue sections (12 $\mu \mathrm{m}$ thick; $n=3$ /animal) were cut in a cryostat microtome (Leica CM 1520, Leica Biosystems, Nussloch, Germany) at $-18^{\circ} \mathrm{C}$, and collected on special-coated, conducting glass slides (indium tin oxide, ITO, Bruker Daltonics, Bremen, Germany) and stored at $-80^{\circ} \mathrm{C}$. Prior analysis, tissue sections were thawed in a desiccator for 1 hour.

\subsection{ToF-SIMS Analysis}


SIMS imaging was performed on an ION-TOF V ToF-SIMS instrument (IONTOF GmbH, Münster, Germany) equipped with a $\mathrm{Bi}_{3}{ }^{+}$cluster ion gun as primary ion source. Data was acquired in high current bunched mode (HBC) [18] with a pulsed primary ion current of $0.23 \mathrm{pA}$ at $25 \mathrm{keV}$ and a maximum ion dose density was $1.5 \times 10^{9}$ ions $/ \mathrm{cm}^{2}$. Scans were acquired in positive and negative mode using the stage "scan macro raster function" with 10 shots per pixel on $0.4 \mathrm{~mm} \times 0.4 \mathrm{~mm}$ areas (patches) with 200 measurements per $\mathrm{mm}$. This yielded a pixel resolution of $5 \mu \mathrm{m}$. This acquisition mode comprises stepwise acquisition patches over the whole tissue area in electrostatic raster mode and stepwise movement of the sample stage. The mass resolution in $\mathrm{HCB}$ mode was about $\mathrm{M} / \Delta \mathrm{M}=5 \times 10^{3}$. All spectra were acquired and processed using Surface Lab software (v. 6.3 ION-TOF). All spectra were calibrated internally to signals of $[\mathrm{C}]^{+},[\mathrm{CH}]^{+}$, $\left[\mathrm{CH}_{2}\right]^{+},\left[\mathrm{CH}_{3}\right]^{+},\left[\mathrm{C}_{5} \mathrm{H}_{15} \mathrm{PNO}_{4}\right]^{+}$and $\left[\mathrm{C}_{27} \mathrm{H}_{45}\right]^{+}$as calibration points in positive mode and [C]', $[\mathrm{CH}]^{-}$, $\left[\mathrm{CH}_{2}\right]^{-},\left[\mathrm{O}^{-},\left[\mathrm{C}_{16} \mathrm{H}_{31} \mathrm{O}_{2}\right]^{-}\right.$and $\left[\mathrm{C}_{18} \mathrm{H}_{35} \mathrm{O}_{2}\right]^{-}$in the negative ion mode. Two mass interval lists of $\mathrm{m} / \mathrm{z}$ values were created by peak search for each of the ion polarities following the search parameters: $\mathrm{S} / \mathrm{N}>3$.

\subsection{MALDI Sample Preparation and Matrix Application}

For MALDI imaging of lipids, 1.5 di-amino-naphthalene (1,5-DAN) matrix was applied to the tissue sections using a TM-sprayer (HTX Technologies, Carrboro, NC, USA) combined with a HPLC pump (Dionex P-580, Sunnyvale, CA, USA). Before spraying, the solvent pump was purged with $70 \% \mathrm{ACN}$ at $500 \mu \mathrm{L} / \mathrm{min}$ for $10 \mathrm{~min}$ followed by, manual rinse of matrix loading loop using a syringe. A matrix solution of $20 \mathrm{mg} / \mathrm{mL} 1,5-\mathrm{DAN}$ in $70 \% \mathrm{ACN}$ was sprayed onto the tissue sections with the following instrumental parameters: nitrogen flow (12 psi), spray temperature $\left(80^{\circ} \mathrm{C}\right)$, nozzle height $(40 \mathrm{~mm})$, five passes with offsets and rotations, and spray velocity $(1250 \mathrm{~mm} / \mathrm{min})$, and isocratic flow of $50 \mu \mathrm{L} / \mathrm{min}$ using $70 \% \mathrm{ACN}$ as pushing solvent.

For protein imaging, tissue sections were subjected to sequential washes of $100 \% \mathrm{EtOH}$ (60 s), 70\% EtOH (30 s), Carnoy's fluid (6:3:1 EtOH/chloroform/acetic acid) (90 s), 100\% EtOH (15 s), 
$\mathrm{H}_{2} \mathrm{O}$ with $0.2 \%$ TFA (60 s), and 100\% EtOH (15 s). 2,5-Dihydrox-yacetophenone (2,5-DHA) was used as matrix compound and applied using a TM Sprayer. A matrix solution of $15 \mathrm{mg} / \mathrm{mL} 2,5$ DHA in $70 \% \mathrm{ACN} / 2 \% \mathrm{CH}_{3} \mathrm{COOH} / 2 \%$ TFA was sprayed onto the tissue sections using the following instrumental parameters: nitrogen flow (10 psi), spray temperature $\left(75^{\circ} \mathrm{C}\right)$, nozzle height $(40 \mathrm{~mm})$, eight passes with offsets and rotations, and spray velocity $(1000 \mathrm{~mm} / \mathrm{min})$, and isocratic flow of $100 \mu \mathrm{L} / \mathrm{min}$ using $70 \% \mathrm{ACN}$ as pushing solvent. Following the matrix deposition, the preparations were recrystallized as described previously[19]. Here, the slides were mounted with copper tape on a top of a Petri dish (100 mm diameter $\times 15 \mathrm{~mm}$ deep, VWR, Stockholm, Sweden) with a filter paper pipetted with $5 \%$ methanol and placed on the lower part of the dish. The glasses were closed and placed in an oven at $85^{\circ} \mathrm{C}$ for $3 \mathrm{~min}$.

\subsection{MALDI-IMS Analysis}

MALDI-IMS was performed on a MALDI TOF/TOF UltrafleXtreme mass spectrometer equipped with SmartBeam II Nd:YAG/355 nm laser. Lipid imaging was performed in reflector negative mode with a source accelerating voltage of $-20 \mathrm{kV}$. A mass range of 200-2500 Da was analyzed with 20 laser shots per pixel at a spatial resolution was $15 \mu \mathrm{m}$ with laser focus was set to minimum. The mass resolution at $\mathrm{m} / \mathrm{z} 800$ was of $M / \Delta M$ 20000. External calibration was carried out using peptide calibration standard I (Bruker Daltonics). Protein MS data were acquired over a mass range of $2-20 \mathrm{kDa}$, running in linear positive mode. A number of 50 laser shots/raster spot were acquired at $1 \mathrm{kHz}$ laser repetition rate with a lateral resolution of $15 \mu \mathrm{m}$ with a laser beam focus set to small. Image data were reconstructed; root mean square (RMS) normalized and visualized using the Flex Imaging v3.0 software (Bruker Daltonics).

\subsection{SIMS Data Processing and Analysis}

For image analysis of SIMS data from the whole tissue scans and burst alignment data, was subjected to multivariate analysis by means of image PCA using Surface Lab Software (v 6.1, 
IONTOF). The cortical areas were assigned using the implemented ROI feature. The assigned regions were then reconstructed with the respective mass interval list using the Mass Explorer of the Surface Lab Software (v 6.1, IONTOF). The data was, centered and univariate scaled.

\subsection{MALDI IMS Data Processing and Analysis}

Prior to analysis, all spectra were calibrated externally using the batch-processing function in Flex Analysis (v 3.0, Bruker Daltonics). Calibration spectra were obtained from calibrant solution spots (Protein Calibration Mix 1, Bruker Daltonics) that were placed adjacent to the tissue slides. Image analysis of the IMS data was performed in SciLS (v2014, Bruker Daltonics). Principal component analysis (PCA) and spatial segmentation using bisecting k-mean clustering was performed in order to identify characteristic lipid distribution patterns and to aid in region of interest (ROI) identification. ROls in aligned imaging MS data were annotated and Average spectra of the annotated ROls were exported as *.csv files from Flexlmaging. All ROI data were imported into Origin (v. 8.1 OriginLab, Northhampton, MA) and peaks and peak widths were detected on average spectra of each ROI using the implemented peak analyzer function. The determined bin borders for peak integration were exported as tab delimited text file followed by binning of all ROI average spectra using an in-house developed R script (peak-bin) as described previously [20]. For confirmation of the lipid and peptide identity, MALDI-LIFT (MS/MS) was performed directly on the plaque deposits in LIFT mode as previously described [21, 22]. Peptide identification was performed through s equence matching using the BioTools software (v. 3.2, Bruker Daltonics), and database search using mascot search engine (MS/MS search, Matrix Science, London, UK) as previously described [23]. Lipid identifications were performed by comparing fragment ions with LIPID MAPS database (www.lipidmaps.org) [21, 22].

\subsection{Multivariate Spectral Analysis Statistical Analysis}


Peak areas for all the ROls from each of the animals were evaluated in a multivariate manner using Orthogonal Projection to Latent Structures by Partial Least Squares-Discriminant Analysis (OPLS-DA) using SIMCA (v. 14.0, Umetrics, Umeå, Sweden). OPLS-DA is an extension to the Partial Least Squares (PLS) regression method that uses the group information coded in a binary matrix $\mathrm{Y}$ to decompose the systematic variation in $\mathrm{X}$ matrix into correlated to $\mathrm{Y}$ (predictive) between-class and uncorrelated to $Y$ (orthogonal) within-class variations [24]. This separation between the predictive and orthogonal components facilitates a straightforward interpretation of the predictive loading vector and provides a direct measure of the influence each of the variables has in the model. The number of relevant components for the models was estimated through cross-validation (CV), by exclusion of one randomized sample for each CV round. Follow up statistical analysis of individual lipid signals and comparisons between the groups were performed with paired, two tailed t-test $(\mathrm{p}<0.05)$. Correlation of the lipid and protein signal for plaque ROls as annotated in MALDI-IMS data was carried out using Pearson correlation.

\section{Results and Discussion}

\subsection{Multivariate Image Analysis of MALDI-IMS and ToF-SIMS data}

In order to investigate $A \beta$ plaque pathology associated lipid changes, ToF-SIMS and MALDI-IMS analysis was performed on brain sections from tgAPPArcSwe mice. As an initial step, the entire imaging data from both imaging modalities was subjected to multivariate image analysis using Principal Component Analysis (PCA).

Image PCA of ToF-SIMS data from tgAPPArcSwe mice revealed major regions of the brain, based on their biochemical identity [25]. While the score (i.e. eigenvalue) images for principal component 1 (PC1), PC2 and PC4 (Figure 1 A, B, C) illustrate the variance over the analyzed area for a specific factor, the biochemical information behind these differences is maintained in the loadings (eigenvectors). Here, a clear distinction from the adjacent anatomical regions could be achieved. 
The image PCA of the Tof-SIMS data did not however reveal any A $\beta$ plaque-like features to be present, as previously reported for MALDI-IMS lipid data [21, 26].

Multivariate image analysis of MALDI-IMS data of tgAPPArcSwe mice was performed using PCA but also spatial segmentation using bisecting k-mean clustering. Here $A \beta$ plaque-like structures were identified to be present throughout the cortex in the PC1 (Figure 1D) and PC7 (Figure 1E).
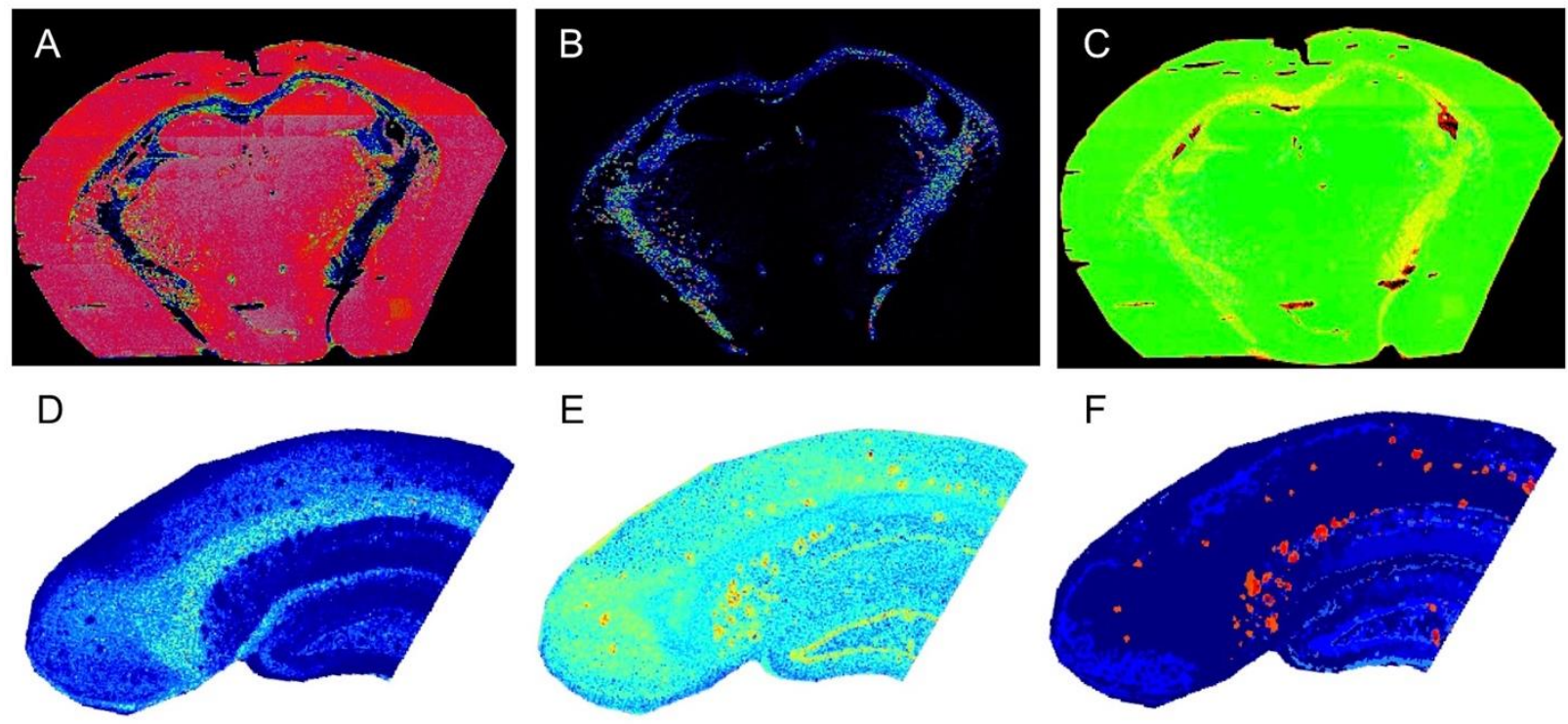

Figure 1. Multivariate image analysis of the Tof-SIMS and MALDI-IMS lipid data. (A-C) Principal component analysis of Tof-SIMS data in revealed clear chemical differences across the brain and allowed for annotation of anatomical regions based on the score images of the different principal components (PC), outlining (A) PC1, the grey matter and the white matter as shown for (B) PC2, (C) PC4.

(D-E) PCA of MALDI-IMS lipid data revealed A $\beta$ plaque like features to be present throughout the cortex and hippocampus. Here, (D) PC1 revealed relative depletion and (E) PC7 an enrichment of lipids signals at the site of plaques, while these scores also highlight other anatomical regions such as the white matter (D) and the $(\mathbf{E})$ grey matter and more detailed the granular layer of the dentate gyrus in the hippocampus. (F) Segmentation analysis of the MALDI-IMS lipid data using cluster analysis (bisecting k-means) revealed plaque specific lipid clusters that allowed for interpretation and correlation analysis. 
While PCA extracts the highest variance in the IMS dataset and provides a variable representation that directly reflects sample representation, due to the bidirectional loading values, interpretation of PCA score images is not always straight forwards. In contrast, spatial segmentation using hierarchical clustering, pairs the variables based on their degree of similarity. The resultant pseudo-objects, i.e. clusters, reflect homogenous groups of variables, with dominating withingroup similarities. Indeed, spatial segmentation of MALD-IMS lipid data provided a clear representation of $A \beta$ plaque-like clusters co-localized with the features revealed by PCA (Figure $1 \mathrm{~F})$.

\subsection{Lipid analysis by ToF-SIMS reveals global changes in sulfatide levels}

Given that the image PCA of the ToF-SIMS data did not reveal any plaque-like features to be present in the transgenic animals, the individual loadings responsible for separation of the extracted anatomical $\mathrm{ROI}$ (Figure $2 \mathrm{~A}$ ) from both control and $\mathrm{AD}$ animals were evaluated in a conventional multivariate manner, through Orthogonal Projection to Latent Structures by Partial Least Squares-Discriminant Analysis (OPLS-DA). Here models for hippocampus (M1:1+2), as well as cortex (M2: 1+2) allowed separation (RX2 cumulative M1: 0,852; M2: 0,904), with strong cross validation matrices ( $Q 2$ cumulative M1: 0,554; M2: 0,854) as indicated in the corresponding score plots (Figure $2 \mathrm{~B}, \mathrm{C}$ ). Investigation of the corresponding loadings highlighted molecular species in the $\mathrm{m} / \mathrm{z} 800-900$ range to underlay this separation. Based on accurate mass assignment these species were identified as sulfatides. Follow-up two class paired t-statistics $(p<0.05)$ was carried out in order to verify the observed changes. Indeed, a significant decrease of several sulfatides (ST) was observed in tgAPPArcSwe animals as compared to controls in both the hippocampus (Figure 2D) and cortex (Figure 2E). Inspection of cumulative sulfatide images from tgAPPArcSwe animals (Figure 2F) and controls (Figure 2G) allowed for visualization of this decrease. 

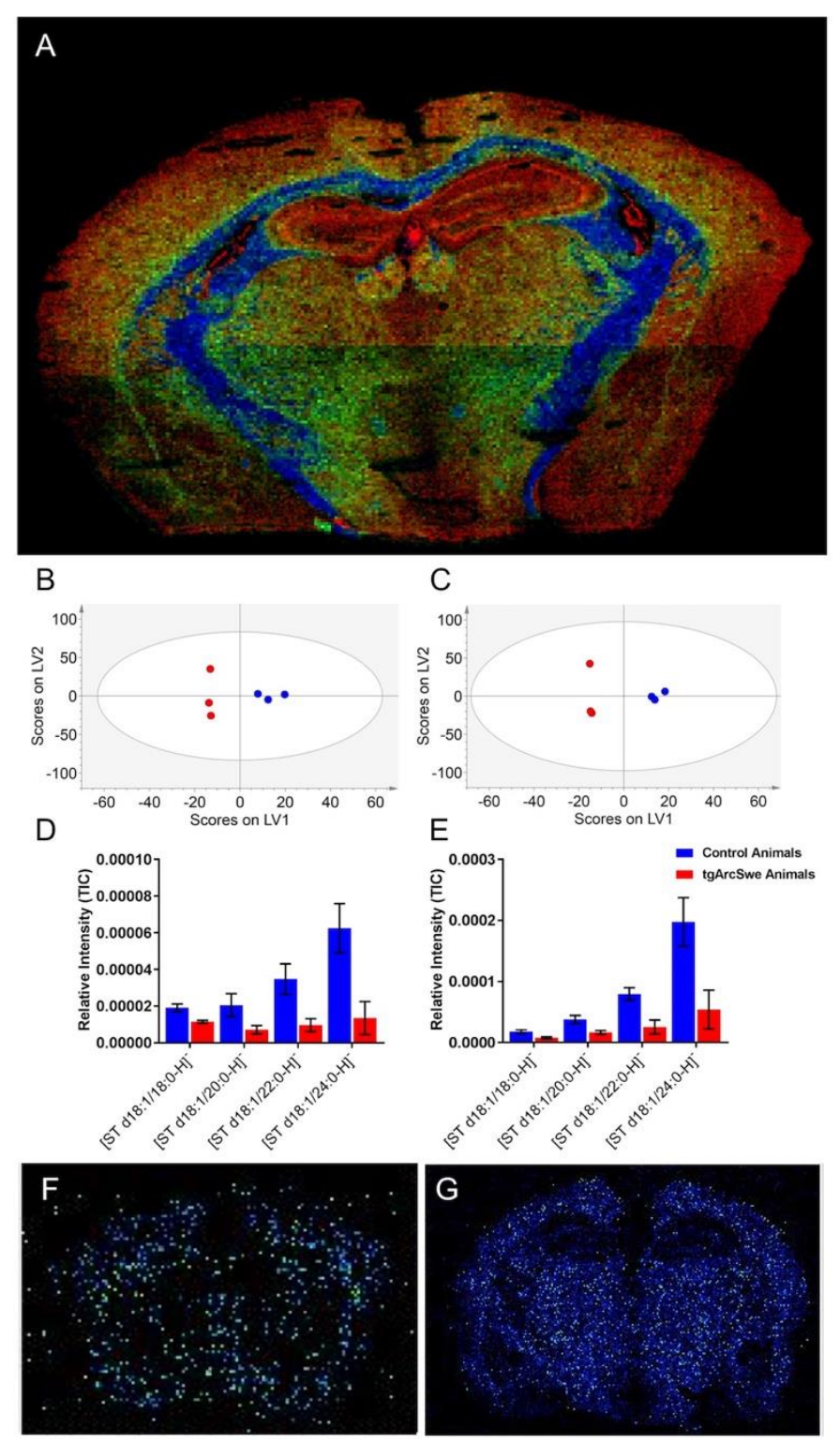

C

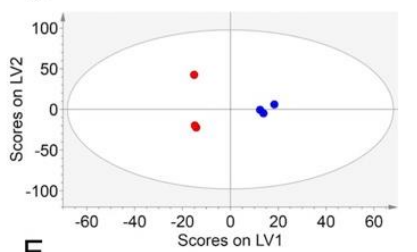

E

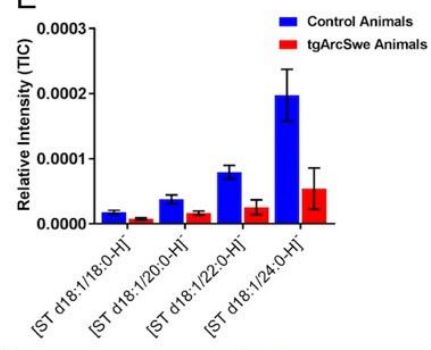

G
Figure 2. Region of interest specific analysis of Tof-SIMS data reveals sulfatide depletion in tgAPPArcSwe mice. (A) Based on the principal component image analysis (see Fig.1), anatomical regions of interest $(\mathrm{ROI})$ comprising hippocampus and cortex were annotated. (B-C) Extracted regional data was subjected to the Orthogonal Projection to Latent Structures by Partial Least Squares-Discriminant Analysis (OPLS-DA). (B) Score plots of a 1+2 model for hippocampus (RX2: 0,852, Q2 cumulative: 0,554), and (C) a 1+2 model for cortex (RX2: 0,904, Q2 cumulative: 0,854) allowed for good separation of the groups. (D-E) Inspection of underlying loadings revealed several sulfatide species to be decreased in $\operatorname{tg} \mathrm{APP}_{\text {ArcSwe }}$ mice as compared to controls in both (D) hippocampus and (E) cortex. (F-G) Inspection of single ion images revealed a much lower signal in (F) AD mice as compared to $(\mathbf{G})$ controls $(p<0.001)$.

In line with the results of the Tof-SIMS analysis, previous MALDI IMS studies on human cortex sections, as well as hippocampal and cortical amyloid plaques in tgAPP Arcswe mice, have demonstrated similar phenomenon [21, 27, 28]. Further, a general brain sulfatide decrease has also been observed in shotgun lipidomic studies of brain homogenates from AD patients and AD mice [29]. Given that the majority of sulfatides in the central nervous system (CNS) are present in myelinating oligodendrocytes [30], this observation likely reflects demyelination and 
neurodegeneration, which is characteristic for progressing AD [31]. Mechanistically, this has been hypothesized to be a result of low density lipoprotein (LDL) receptor-mediated endocytosis of ST containing lipoproteins, such as ApoE. This ST-ApoE complex are target to lysosomal degradation $[32,33]$. Indeed, the increased production of $A \beta$ in transgenic mice has been shown to require an increase in ApoE-mediated clearance [34].

\subsection{MALDI-IMS highlights A $\beta$ plaque associated sphingolipid and phospholipid changes}

In contrast to the Tof-SIMS data, the multivariate image analysis of the MALDI-IMS lipid data revealed clear $A \beta$ plaque-like features to be present throughout the hippocampus and cortex of $\operatorname{tg} \mathrm{APP}_{\text {Arccswe }}$ mice. Co-localization analysis of the observed $A \beta$ plaque corresponding pseudoclusters observed in the spatial segmentation (Figure $3 \mathrm{~A}$ ) was carried out to facilitate the identification of the molecular species underlying these. In agreement with previously reported data [21, 26], several signals in the $\mathrm{m} / \mathrm{z}$ 500-900 range, comprising sphingolipids (ceramides, sulfatides, and gangliosides, as well as phospholipids, in particular phospatidylinositols) were identified. Here, the ceramides (Cer) including [Cer d18:1/14:0-H] (Figure 3B) and [Cer $\mathrm{d} 18: 1 / 18: 0-\mathrm{H}]^{-}$(Figure $3 \mathrm{C}$ ), displayed localization to the $\mathrm{A} \beta$ plaque-like structures. Among sulfatides (ST), a previously reported general patter of depletion at the plaques was observed [21] (Figure 3D-F). Herein, this depletion was most apparent for the long chain fatty acid [ST $\mathrm{d} 18: 1 / 24: 0-\mathrm{H}]^{-}$and [ST d18:1/22:0-H]', and far less for the [ST d18:1/20:0-H] species (Figure 3DF). Further, localization pattern of monosialo-gangliosides (GM) with C18:0 fatty acid moiety was apparent for the previously reported GM3 (Figure 3G) and GM2 (Figure 3H). Interestingly, the localization of the corresponding GM1 ganglioside was most prominent in the cluster corresponding to the center of the $A \beta$ plaque-like structures (Figure $3 \mathrm{I}$ ). Further, lysophosphatidylinositol (LPI, [LPI 18:0-H] ${ }^{-}$; Figure 3J), as well as arachidonic acid (AA) conjugated phosphatidylinositols (PI, Figure 3K, L) displayed plaque specific localization, however with a pronounced localization a pseudo-cluster representing the peripheral structure of plaques. 

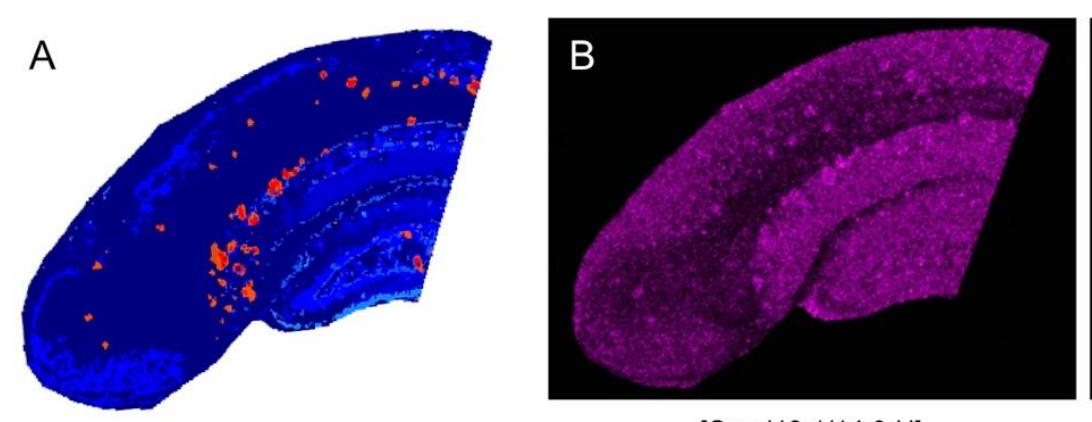

[Cer d18:1/14:0-H]'

$\mathrm{m} / \mathrm{z} 508.4$

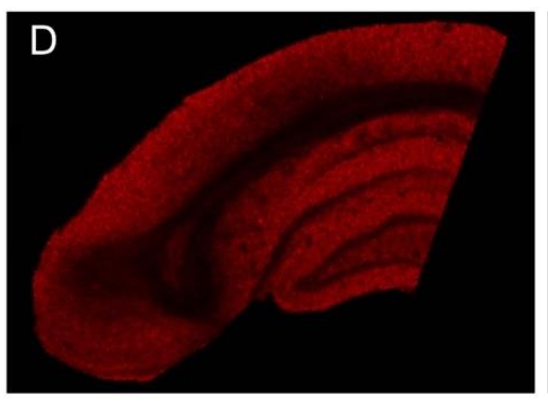

[ST d18:1/20:0-H] $\mathrm{m} / \mathrm{z} 834.6$

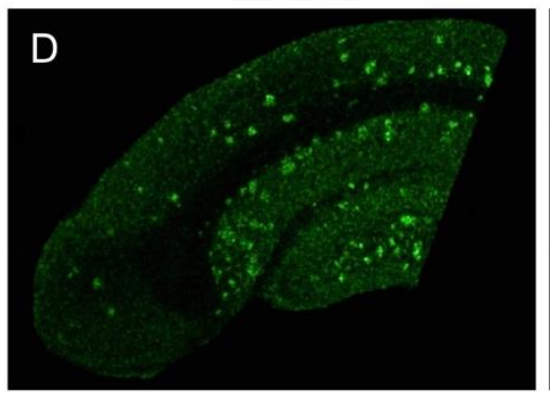

[GM3 d18:1/18:0-H] $\mathrm{m} / \mathrm{z} 1179.7$

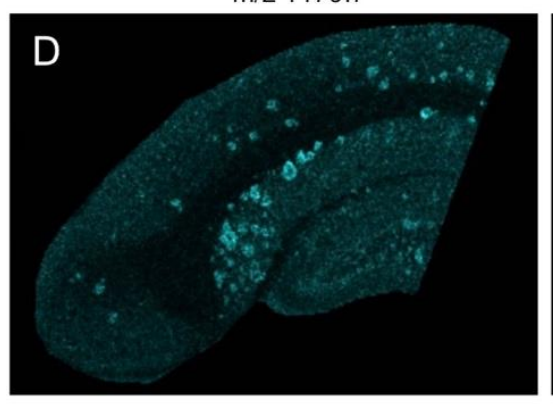
[LPI 18:0-H]
m/z 599.3

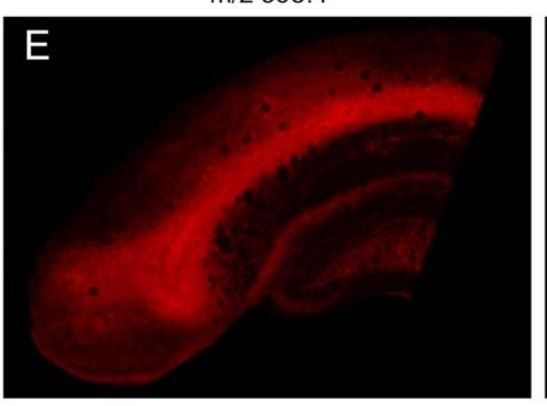

[ST d18:1/22:0-H] $\mathrm{m} / \mathrm{z} 862.6$

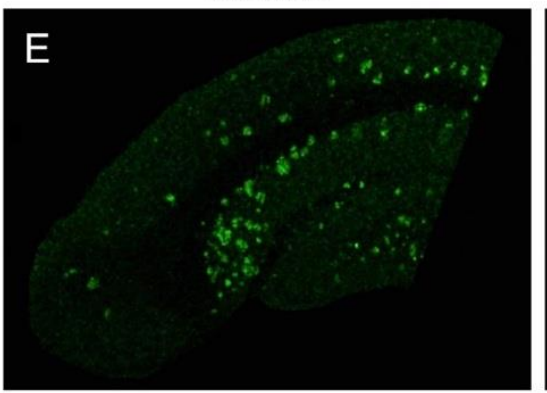

[GM2 d18:1/18:0-H]

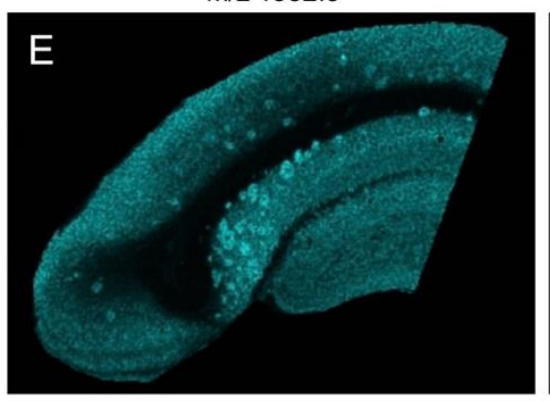

[PI 16:0/20:4-H] $\mathrm{m} / \mathrm{z} 857.5$ $\mathrm{m} / \mathrm{z} 1382.8$

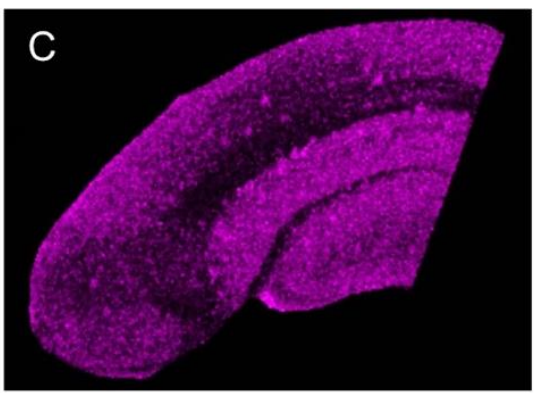

[Cer d18:1/18:0-H]

$\mathrm{m} / \mathrm{z} 564.6$

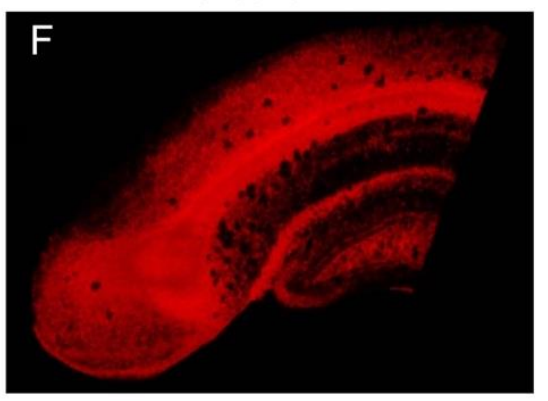

[ST d18:1/24:0-H] $\mathrm{m} / \mathrm{z} 890.6$

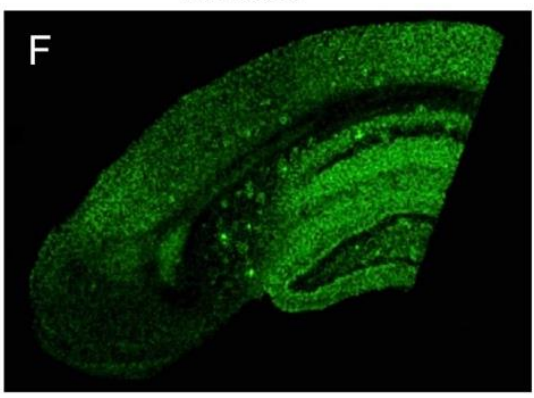

[GM1 d18:1/18:0-H] $\mathrm{m} / \mathrm{z} 1544.9$

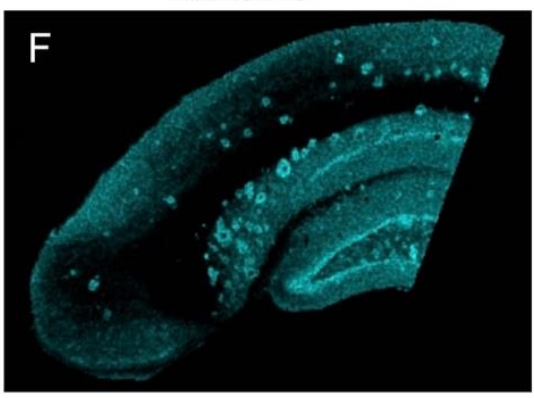

[PI 18:0/20:4-H] $\mathrm{m} / \mathrm{z} 885.6$

Figure 3. MALDI-IMS lipid imaging reveal plaque specific changes in sphingolipids and inositols. (A)

Spatial segmentation of lipid data allowed for correlation analysis and identification of lipid signals associated with the identified $A \beta$ plaque specific pseudo-clusters. (B-C) Localization of several ceramides to plaque like features. (D-F) A depletion of sulfatides, along with and enrichment of a-series ganglioside 
(G-I) was observed at the plaques. Further, arachidonic acid (AA) containing phosphatidyinositols (PI) and associated lyso-PI species (LPI) were also found to be enriched in the plaques (J-L).

A number of studies have suggested a general role of sphingolipids, including ceramides [29, 35], sulfatides [29, 33], and gangliosides [36-39], in AD pathogenesis. In general, ceramide elevation, and the earlier discussed, sulfatide decrease, have previously been demonstrated in several studies [29, 35]. Similarely, tissue levels of GM2 and GM3 species have been found to be increased in multiple brain regions in both human AD and $\operatorname{tg} A P P_{\text {swe }}$ mice $[37,40,41]$, which is well in line with the present data. Further, previous MALDI IMS studies have indeed demonstrated some of the sphingolipids observed here to be associated with $A \beta$ plaque pathology in $A D$ mice $[21,28]$. Here, cell death associated acceleration of lysosomal degradation of neuronal gangliosides, such as GM1, and sulfatides present in $A \beta$ plaque region, has been suggested to be a possible basis for these observations $[42,43]$. Interestingly, previous MALDI imaging studies have not demonstrated GM1 species to localize to the $A \beta$ plaque pathology, but rather remain unaltered $[21,28]$. Still, this species has been suggested be altered in AD, with increased levels in CSF [36], and a decrease in brain homogenates of $A D$ brains [42, 44, 45]. A possible explanation of this could be lack of specificity of the antibodies used in the previous immunoassaybased studies. Alternatively, a site-specific enrichment of GM1 at A $\beta$ plaque pathology with a general, brain-wide and more dominant decrease could be the cause.

In addition, to the sphingolipid species, several phosphoinositol species, including LPI and PI were detected in the peripheral, diffuse structures of cored plaques. As demonstrated by MALDI-IMS, AA containing phospholipids are essential precursors in eicosanoid synthesis underlying microglial and astroglial mediated inflammatory response mechanisms [46]. Likewise LPI, the corresponding degradation product of LPI, a process mediated by cytosolic phospholipase A2 $\left(P L A_{2}\right)$ activity, has been shown to regulate neuroinflammation and neurodegeneration in AD [47, 
48]. Therefore, the presence of these inositols highlights the neuroinflammatory processes taking place at the site of $A \beta$ plaque pathology.

\subsection{MALDI-IMS reveals inhomogeneous $A \beta$ peptide distribution across $A \beta$ plaques}

In order to verify the nature of the $A \beta$ plaque-like structures identified in the MALDI-IMS lipid analysis, MALDI-IMS peptide imaging was carried out on the consecutive tissue sections. As before multivariate image analysis was carried out through PCA and segmentation. PCA revealed clear $A \beta$-plaque like structures to be present in the first PC score image (Figure 4A). Further spatial segmentation, highly corresponding to the PC1 score image, highlighted heterogeneity within single large deposits (Figure 4B). This was more apparent than the similar made for the spatial segmentation of the MALDI-IMS lipid data (Figure 3A). Investigation of associated loading plots and underlying and pseudo-clusters revealed localization of peptides in the $\mathrm{m} / \mathrm{z} 4000-5000$ range, suggesting that the underlying signals correspond to $A \beta$ peptides. Based on accurate mass values assignment, these peptides were identified as $A \beta$ peptides. Here, in agreement with previous

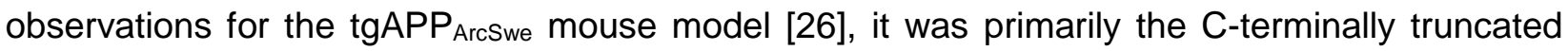
peptides, including $A \beta 1-37$ arc, $A \beta 1-38$ arc, $A \beta 1-39$ arc, and $A \beta 1-40$ arc (Figure $4 C-F)$ that were enriched in the $A \beta$ deposits. Interestingly, while the $A \beta 1-37$ arc, and $A \beta 1-39$ arc peptide species appeared to have a homogenous distribution, the $A \beta 1-40 \mathrm{arc}$, and to some extent $A \beta 1-38$ arc peptides, appeared to display a gradient with highest signal intensity to be present in the center of the plaques. 


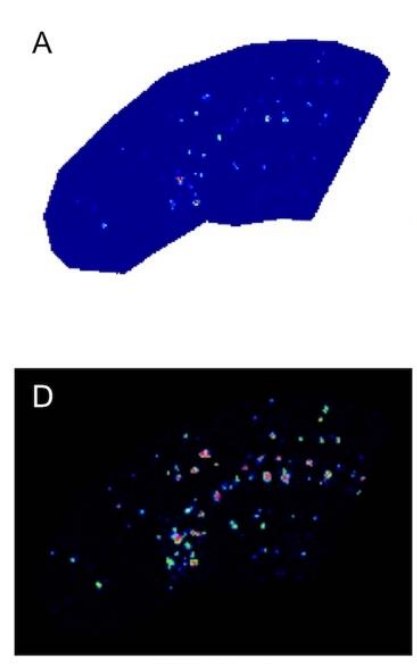

[Aß1-38 arc]

$\mathrm{m} / \mathrm{z} 4059.3$
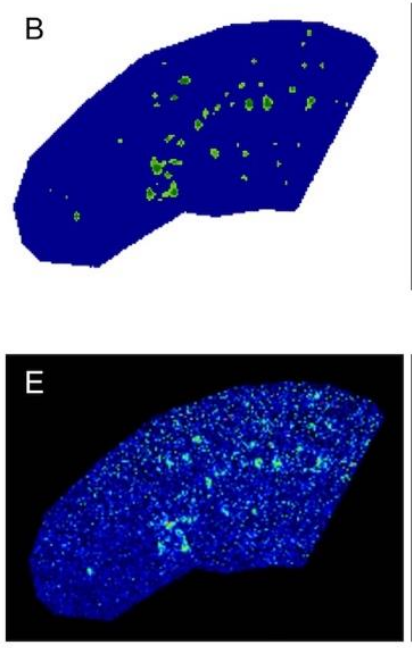

[Aß1-39 arc] $\mathrm{m} / \mathrm{z} 4157.6$

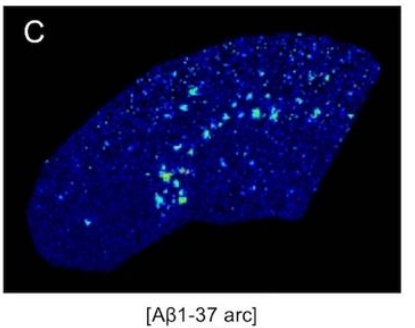

$\mathrm{m} / \mathrm{z} 4002.3$

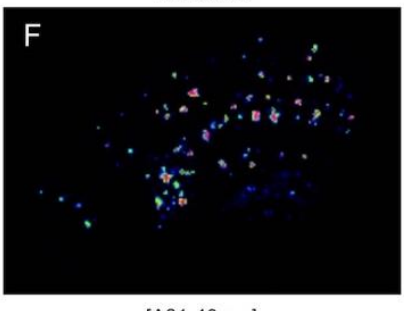

[AB1-40 arc] $\mathrm{m} / \mathrm{z} 4257.3$

Figure 4. MALDI-IMS peptide imaging reveal heterogenous $A \beta$ peptide distribution in plaques. (A) PC1 score image of principal component image analysis of MALDI-IMS peptide data identified presence of $A \beta$ plaque like features. (B) Spatial segmentation analysis allowed for straightforward interpretation of localization patterns into various pseudo-clusters. (C-F) Here C-terminally truncated peptides displayed major localization to the $A \beta$ deposits. In particular, the (D) AB1-38arc and (F) A $A 1-40$ arc displayed a signal gradient across the plaques, while the (C) A 1-37 and (E) Aß1-39 displayed a homogenous distribution.

$A \beta$ plaques consist of $\beta$-sheet rich fibrils formed by differentially truncated $A \beta$ peptide isoforms [49]. Consequently, morphological heterogeneity within plaques, such as a core formation has been linked to structural transitions of different $A \beta$ isoforms during the aggregation process [50, 51]. Generally, the longer $A \beta 1-42$ isoform, which is more prone to aggregate than shorter species, such as $A \beta 1-40$, and has been shown to be the main constituent of protofibrils [52-55]. Here however, the levels of $A \beta 1-42 a r c$ isoform are very limited. This is not surprising given the significant overexpression of the, human APP in the $\operatorname{tg} \mathrm{APP}_{\text {ArcSwe }}$ mice, and the previously reported dominating levels of $A \beta 1-40$ arc, rather than the $A \beta 1-42$ arc peptide, in these mice $[23,56,57]$. Further, given the increased aggregation propensity of the $A \beta$ peptides with the Arctic mutation, 
the aggregation of the A $\beta 1-40$ arc species, and many others C-terminally truncated species will be accelerated [56].

Interestingly, the $A \beta 1-37$ arc and $A \beta 1-39$ arc peptides appeared to be more homogenously distributed whereas the longer 1-40arc appears to exhibit a signal gradient some of the across the plaques. These $\mathrm{C}$-terminally truncated $A \beta$ species, have been shown to result from sequential $\mathrm{Y}^{-}$ secretase processing of the APP C-terminal fragment ( $\beta$-CTF) at Thr-48 or Leu-49, with consecutive loss of tripeptides or longer sequences [58] [59-61]. Therefore, the differences in distribution of $A \beta$ 1-37 and $A \beta$ 1-39 could be a consequence of differential processing of full length $A \beta$ peptides.

\subsection{Altered GM metabolism is associated with $A \beta$ plaque core formation}

Finally, in order to further investigate the relation between the lipid and peptide MALDI-IMS data, individual $A \beta$ plaques were annotated as $\mathrm{ROI}$ and exported for each of the biological replicates ( $n=3,10-15$ plaques). Lipids and peptides enriched in the pseudo-cluster corresponding to either the middle or the periphery of the plaques were evaluated through correlation analysis. Here, a weak but significant relationship between $G M 1$ and the $A \beta 1-40\left(R^{2}=0.4518, p<0.001\right)$ (Figure $\left.5 A\right)$, but not the other species, was observed. Indeed, inspection of the single ion images highlight that GM1 is primarily localized at the center of the deposits (Figure 5B), in contrast to GM2 (Figure 5C) and GM3 (Figure 5E) that in fact both displayed a complementary pattern to the periphery of the plaque as highlighted in overlay images (Figure 5D, F). This is further well in correspondence with some of the $A \beta$ isoforms detected on a consecutive section. Here, $A \beta 1-37$ peptide showed localization to the diffuse periphery of the plaques similar to GM2 and GM3 (Figure 5G), while $A \beta 1-40$ is strongly localized to the plaque core (Figure $5 \mathrm{H}$ ). 

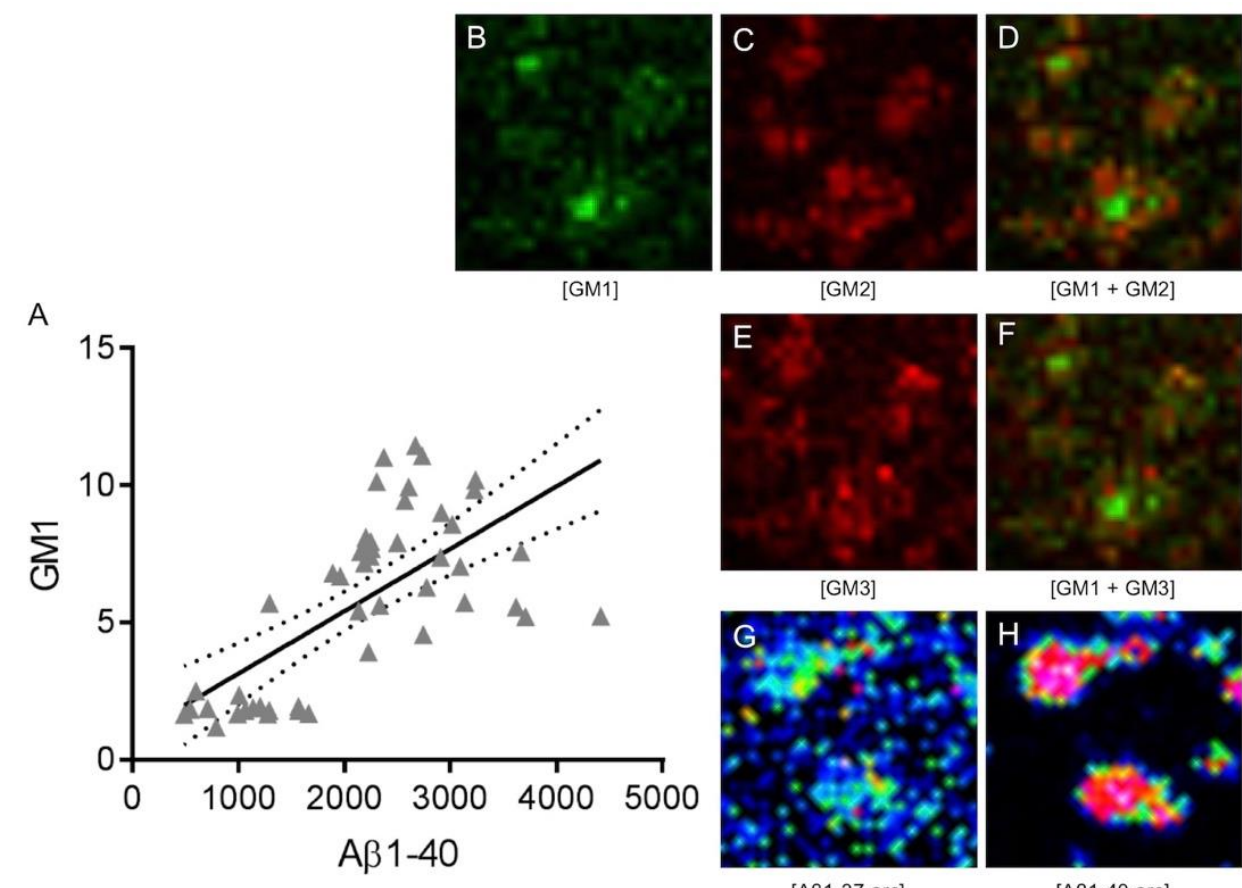

$[\mathrm{GM} 1+\mathrm{GM} 2]$

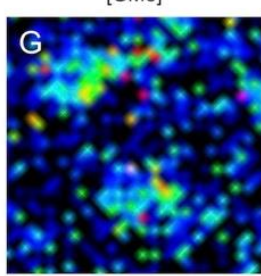

[AB1-37 arc]

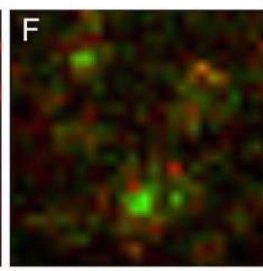

$[\mathrm{GM} 1+\mathrm{GM} 3]$

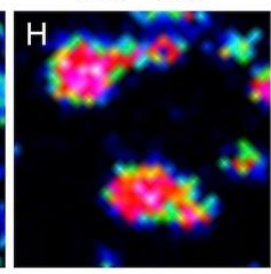

$[\mathrm{A} \beta 1-40 \mathrm{arc}]$

Figure 5. Heterogeneous ganglioside metabolism within a single plaque is associated with $A \beta$ peptide profile. (A) Correlation analysis between lipids and peptides in MALDI-IMS revealed a significant relationship between the $\mathrm{GM} 1$ and $A \beta 1-40$ arc $(R 2=0.4518, p<0.001)$. (B-F) Investigation of single ion images revealed core specific localization of (B) GM1 (arrows), and more general localization of (C) GM2 to the plaques, revealed their (D) complementary signal as highlighted by the overlay image. (E-F) The same was true for the (E) GM3 species, as indicated by the (F) overlay image. For A peptides, a homogenous distribution of (G) $A \beta 1$-37arc across a plaque, in difference to a clear gradient, for the (H) $A \beta 1$ 40arc underlined the clear correlation of the longer peptide with the GM1 species.

As discussed above, previous studies have demonstrated a brain-wide decease of the GM1 species, and an increase of this ganglioside in CSF [36, 42, 44, 45]. A possible explanation to this could be a site-specific enrichment of gangliosides (such as within $A \beta$ plaque), with a global decrease. Indeed, as presented here, the GM1 species localized specifically to the center of larger plaques. At the same time, this appears to be associated with an increase in the A $\beta 1-40$ arc signal. Previous, immunohistochemical characterization of plaque phenotypes, showed prominent $A \beta x-$ 
40 immunoreactivity within plaque cores, while $A \beta x-42$ was found to stain mostly the corona [57, 62, 63]. Therefore, given a clear correlation between $\mathrm{GM} 1$ and A $\mathrm{A} 1-40$ arc could indicate processes associated with $A \beta$ plaque core formation. GM1 has been proposed to be essential in $A D$ pathology, through e.g. a suggested formation of $G M 1$-bound $A \beta(G-A \beta)$ species acting both as neuroprotective mechanism and promoting seed of $A \beta$ aggregation [64-66]. Further, in line with these observations, the complementary pattern of the GM1 with the GM2/GM3 species, as well as presence of the PI, and LPI, further suggest the likely macrophage mediated lysosomal degradation of gangliosides at the plaque periphery, but not in the center of the $A \beta$ plaques [46, 67].

\section{Conclusions}

In the present study. Tof-SIMS- and MALDI-MS-based multimodal imaging mass spectrometry was employed to investigate the lipid-protein interactions associated with $A \beta$ plaque pathology in thetgAPPArcSwe mouse model of AD. Tof-SIMS- and MALDI IMS and identified an AD-associated decrease of sulfatides in different brain regions presumably associated with axon demyelination and neurodegeneration. MALDI IMS analyses provided comprehensive information on A $\beta$ plaqueassociated molecular species, identifying several lipids subclasses and $A \beta$ peptide isoforms on a single plaque level. Taken together, we demonstrate the potential of both MALDI- and Tof-SIMSbased IMS for studying various molecular species associated with AD pathology. The results highlight a clear role of several sphingolipid classes to be associated with the AD pathology, revealing heterogeneous a-series ganglioside metabolism to be associated with plaque core and periphery, and to correlate with the corresponding $A \beta$ species in the respective morphological domains of individual plaques.

\section{Acknowledgments}

The Swedish Research Council VR (\#2014-6447, JH; \#2013-2546, HZ), the European Research 
Council (\#681712, HZ), the Royal Society of Arts and Sciences in Gothenburg KVVS (JH), Alzheimerfonden $(\mathrm{JH}, \mathrm{KB})$, Demensfonden $(\mathrm{JH})$, Hjärnfonden $(\mathrm{HZ}, \mathrm{KB})$, the Knut and Alice Wallenberg Foundation (HZ), Jeanssons Stiftelsen (JH), Ahlén Stiftelsen (JH), Stiftelsen Gamla Tjänarinnor (JH, KB, WM), Stohnes Stiftelse (JH, WM), Torsten Söderberg Foundation (KB), Frimurarestiftelsen $(\mathrm{HZ})$ and Stiftelsen Wilhelm och Martina Lundgrens Vetenskapsfond $(\mathrm{JH})$ are acknowledged for financial support. Parts of this work was performed at the Gothenburg University Imaging Mass Spectrometry Platform (go:ims; www.go_ims.gu.se), where Jörg Hanrieder is an affiliated PI. Parts of the work was also supported by the UK Dementia Research Institute. The authors declare no conflict of interest.

\section{References}

[1] P. Scheltens, K. Blennow, M.M. Breteler, B. de Strooper, G.B. Frisoni, S. Salloway, W.M. Van der Flier, Alzheimer's disease, Lancet (London, England), 388 (2016) 505-517.

[2] J. Hardy, D.J. Selkoe, Medicine - The amyloid hypothesis of Alzheimer's disease: Progress and problems on the road to therapeutics, Science, 297 (2002) 353-356.

[3] J.A. Hardy, G.A. Higgins, Alzheimer's disease: the amyloid cascade hypothesis, Science, 256 (1992) 184-185.

[4] D.J. Selkoe, J. Hardy, The amyloid hypothesis of Alzheimer's disease at 25 years, EMBO molecular medicine, 8 (2016) 595-608.

[5] H. Zetterberg, K. Blennow, E. Hanse, Amyloid beta and APP as biomarkers for Alzheimer's disease, Experimental gerontology, 45 (2010) 23-29.

[6] G. Di Paolo, T.-W. Kim, Linking Lipids to Alzheimer's Disease: Cholesterol and Beyond, Nature Reviews. Neuroscience, 12 (2011) 284-296.

[7] C.A. Ross, M.A. Poirier, Protein aggregation and neurodegenerative disease, Nat. Med., 10 (2004) S10-S17.

[8] P.K. Auluck, G. Caraveo, S. Lindquist, Synuclein: Membrane Interactions and Toxicity in Parkinson's Disease, Annu Rev Cell Dev Biol, 26 (2010) 211-233.

[9] J. Fantini, N. Yahi, Molecular insights into amyloid regulation by membrane cholesterol and sphingolipids: common mechanisms in neurodegenerative diseases, Expert Rev. Mol. Med., 12 (2010).

[10] P.J. Barrett, Y. Song, W.D. Van Horn, E.J. Hustedt, J.M. Schafer, A. Hadziselimovic, A.J. Beel, C.R. Sanders, The amyloid precursor protein has a flexible transmembrane domain and binds cholesterol, Science, 336 (2012) 1168-1171.

[11] C.-C. Liu, T. Kanekiyo, H. Xu, G. Bu, Apolipoprotein E and Alzheimer disease: risk, mechanisms and therapy, Nat Rev Neurol, 9 (2013) 106-118.

[12] D.S. Cornett, M.L. Reyzer, P. Chaurand, R.M. Caprioli, MALDI imaging mass spectrometry: molecular snapshots of biochemical systems, Nature Methods, 4 (2007) 828-833.

[13] L.A. McDonnell, R.M. Heeren, Imaging mass spectrometry, Mass spectrometry reviews, 26 (2007) 606-643. 
[14] R.M. Caprioli, T.B. Farmer, J. Gile, Molecular imaging of biological samples: localization of peptides and proteins using MALDI-TOF MS, Anal Chem, 69 (1997) 4751-4760.

[15] F. Benabdellah, A. Seyer, L. Quinton, D. Touboul, A. Brunelle, O. Laprevote, Mass spectrometry imaging of rat brain sections: nanomolar sensitivity with MALDI versus nanometer resolution by TOF-SIMS, Analytical and Bioanalytical Chemistry, 396 (2010) 151-162. [16] J. Hanrieder, N.T.N. Phan, M.E. Kurczy, A.G. Ewing, Imaging Mass Spectrometry in Neuroscience, ACS Chemical Neuroscience, 4 (2013) 666-679.

[17] A. Lord, H. Kalimo, C. Eckman, X.-Q. Zhang, L. Lannfelt, L.N.G. Nilsson, The Arctic Alzheimer mutation facilitates early intraneuronal $A \beta$ aggregation and senile plaque formation in transgenic mice, Neurobiology of Aging, 27 (2006) 67-77.

[18] R.N. Sodhi, Time-of-flight secondary ion mass spectrometry (TOF-SIMS):--versatility in chemical and imaging surface analysis, The Analyst, 129 (2004) 483-487.

[19] J. Yang, R.M. Caprioli, Matrix Sublimation/Recrystallization for Imaging Proteins by Mass Spectrometry at High Spatial Resolution, Analytical Chemistry, 83 (2011) 5728-5734.

[20] J. Hanrieder, A. Ljungdahl, M. Falth, S.E. Mammo, J. Bergquist, M. Andersson, L-DOPAinduced dyskinesia is associated with regional increase of striatal dynorphin peptides as elucidated by imaging mass spectrometry, Molecular \& cellular proteomics : MCP, 10 (2011) M111.009308.

[21] I. Kaya, D. Brinet, W. Michno, S. Syvanen, D. Sehlin, H. Zetterberg, K. Blennow, J. Hanrieder, Delineating Amyloid Plaque Associated Neuronal Sphingolipids in Transgenic Alzheimer's Disease Mice (tgArcSwe) Using MALDI Imaging Mass Spectrometry, ACS Chem Neurosci, (2017).

[22] I. Kaya, W. Michno, D. Brinet, Y. lacone, G. Zanni, K. Blennow, H. Zetterberg, J. Hanrieder, Histology-Compatible MALDI Mass Spectrometry Based Imaging of Neuronal Lipids for Subsequent Immunofluorescent Staining, Analytical Chemistry, (2017).

[23] L. Carlred, W. Michno, I. Kaya, P. Sjovall, S. Syvanen, J. Hanrieder, Probing Amyloid-beta Pathology in transgenic Alzheimer's disease (tgArcSwe) mice using MALDI Imaging Mass Spectrometry, J Neurochem, (2016).

[24] M. Bylesjö, M. Rantalainen, O. Cloarec, J.K. Nicholson, E. Holmes, J. Trygg, OPLS discriminant analysis: combining the strengths of PLS-DA and SIMCA classification, Journal of Chemometrics, 20 (2006) 341-351.

[25] J. Hanrieder, P. Malmberg, O.R. Lindberg, J.S. Fletcher, A.G. Ewing, Time-of-flight secondary ion mass spectrometry based molecular histology of human spinal cord tissue and motor neurons, Analytical Chemistry, 85 (2013) 8741-8748.

[26] L. Carlred, W. Michno, I. Kaya, P. Sjovall, S. Syvanen, J. Hanrieder, Probing amyloid-beta pathology in transgenic Alzheimer's disease (tgArcSwe) mice using MALDI imaging mass spectrometry, Journal of neurochemistry, 138 (2016) 469-478.

[27] D. Yuki, Y. Sugiura, N. Zaima, H. Akatsu, Y. Hashizume, T. Yamamoto, M. Fujiwara, K.

Sugiyama, M. Setou, Hydroxylated and non-hydroxylated sulfatide are distinctly distributed in the human cerebral cortex, Neuroscience, 193 (2011) 44-53.

[28] I. Kaya, D. Brinet, W. Michno, M. Başkurt, H. Zetterberg, K. Blenow, J. Hanrieder, Novel Trimodal MALDI Imaging Mass Spectrometry (IMS3) at $10 \mu \mathrm{m}$ Reveals Spatial Lipid and Peptide Correlates Implicated in A $\beta$ Plaque Pathology in Alzheimer's Disease, ACS Chemical Neuroscience, 8 (2017) 2778-2790.

[29] X. Han, M.H. D, D.W. McKeel, Jr., J. Kelley, J.C. Morris, Substantial sulfatide deficiency and ceramide elevation in very early Alzheimer's disease: potential role in disease pathogenesis, $J$ Neurochem, 82 (2002) 809-818.

[30] Y. Hirahara, T. Wakabayashi, T. Mori, T. Koike, I. Yao, M. Tsuda, K. Honke, H. Gotoh, K. Ono, H. Yamada, Sulfatide species with various fatty acid chains in oligodendrocytes at different developmental stages determined by imaging mass spectrometry, J Neurochem, (2016). 
[31] S. Mitew, M.T. Kirkcaldie, G.M. Halliday, C.E. Shepherd, J.C. Vickers, T.C. Dickson, Focal demyelination in Alzheimer's disease and transgenic mouse models, Acta neuropathologica, 119 (2010) 567-577.

[32] H. Cheng, Y. Zhou, D.M. Holtzman, X. Han, Apolipoprotein E mediates sulfatide depletion in animal models of Alzheimer's disease, Neurobiol Aging, 31 (2010) 1188-1196.

[33] X. Han, Potential mechanisms contributing to sulfatide depletion at the earliest clinically recognizable stage of Alzheimer's disease: a tale of shotgun lipidomics, J Neurochem, 103 Suppl 1 (2007) 171-179.

[34] Y. Zeng, X. Han, Sulfatides facilitate apolipoprotein E-mediated amyloid-beta peptide clearance through an endocytotic pathway, J Neurochem, 106 (2008) 1275-1286.

[35] R.G. Cutler, J. Kelly, K. Storie, W.A. Pedersen, A. Tammara, K. Hatanpaa, J.C. Troncoso, M.P. Mattson, Involvement of oxidative stress-induced abnormalities in ceramide and cholesterol metabolism in brain aging and Alzheimer's disease, Proceedings of the National Academy of Sciences of the United States of America, 101 (2004) 2070-2075.

[36] K. Blennow, P. Davidsson, A. Wallin, P. Frcdman, C.G. Gottfries, J.E. Månsson, L. Svennerholm, Differences in cerebrospinal fluid gangliosides between "probable Alzheimer's disease" and normal aging, Aging Clinical and Experimental Research, 4 (1992) 301-306. [37] Z. Pernber, K. Blennow, N. Bogdanovic, J.E. Mansson, M. Blomqvist, Altered distribution of the gangliosides GM1 and GM2 in Alzheimer's disease, Dementia and geriatric cognitive disorders, 33 (2012) 174-188.

[38] K. Yanagisawa, Role of gangliosides in Alzheimer's disease, Biochimica et biophysica acta, 1768 (2007) 1943-1951.

[39] J. McLaurin, T. Franklin, P.E. Fraser, A. Chakrabartty, Structural transitions associated with the interaction of Alzheimer beta-amyloid peptides with gangliosides, The Journal of biological chemistry, 273 (1998) 4506-4515.

[40] L. Barrier, S. Ingrand, M. Damjanac, A. Rioux Bilan, J. Hugon, G. Page, Genotype-related changes of ganglioside composition in brain regions of transgenic mouse models of Alzheimer's disease, Neurobiol Aging, 28 (2007) 1863-1872.

[41] R.B. Chan, T.G. Oliveira, E.P. Cortes, L.S. Honig, K.E. Duff, S.A. Small, M.R. Wenk, G. Shui, G. Di Paolo, Comparative Lipidomic Analysis of Mouse and Human Brain with Alzheimer Disease, Journal of Biological Chemistry, 287 (2012) 2678-2688.

[42] I. Kracun, H. Rosner, V. Drnovsek, M. Heffer-Lauc, C. Cosovic, G. Lauc, Human brain gangliosides in development, aging and disease, The International journal of developmental biology, 35 (1991) 289-295.

[43] T. Kolter, K. Sandhoff, Lysosomal degradation of membrane lipids, FEBS letters, 584 (2010) $1700-1712$.

[44] I. Kracun, S. Kalanj, J. Talan-Hranilovic, C. Cosovic, Cortical distribution of gangliosides in Alzheimer's disease, Neurochemistry International, 20 (1992) 433-438.

[45] N.J. Haughey, V.V. Bandaru, M. Bae, M.P. Mattson, Roles for dysfunctional sphingolipid metabolism in Alzheimer's disease neuropathogenesis, Biochimica et biophysica acta, 1801 (2010) 878-886.

[46] D. Xu, T. Omura, N. Masaki, H. Arima, T. Banno, A. Okamoto, M. Hanada, S. Takei, S. Matsushita, E. Sugiyama, M. Setou, Y. Matsuyama, Increased arachidonic acid-containing phosphatidylcholine is associated with reactive microglia and astrocytes in the spinal cord after peripheral nerve injury, Scientific reports, 6 (2016) 26427.

[47] G.S. Moses, M.D. Jensen, L.F. Lue, D.G. Walker, A.Y. Sun, A. Simonyi, G.Y. Sun, Secretory PLA2-IIA: a new inflammatory factor for Alzheimer's disease, Journal of neuroinflammation, 3 (2006) 28.

[48] J.R. Sundaram, E.S. Chan, C.P. Poore, T.K. Pareek, W.F. Cheong, G. Shui, N. Tang, C.M. Low, M.R. Wenk, S. Kesavapany, Cdk5/p25-induced cytosolic PLA2-mediated lysophosphatidylcholine production regulates neuroinflammation and triggers 
neurodegeneration, The Journal of neuroscience : the official journal of the Society for Neuroscience, 32 (2012) 1020-1034.

[49] E. Portelius, N. Bogdanovic, M.K. Gustavsson, I. Volkmann, G. Brinkmalm, H. Zetterberg, B. Winblad, K. Blennow, Mass spectrometric characterization of brain amyloid beta isoform signatures in familial and sporadic Alzheimer's disease, Acta neuropathologica, 120 (2010) 185193.

[50] T.H. Huang, D.S. Yang, P.E. Fraser, A. Chakrabartty, Alternate aggregation pathways of the Alzheimer beta-amyloid peptide. An in vitro model of preamyloid, J Biol Chem, 275 (2000) 36436-36440.

[51] D. Jiang, I. Rauda, S. Han, S. Chen, F. Zhou, Aggregation pathways of the amyloid beta(142) peptide depend on its colloidal stability and ordered beta-sheet stacking, Langmuir, 28 (2012) 12711-12721.

[52] E. McGowan, F. Pickford, J. Kim, L. Onstead, J. Eriksen, C. Yu, L. Skipper, M.P. Murphy, J. Beard, P. Das, K. Jansen, M. Delucia, W.L. Lin, G. Dolios, R. Wang, C.B. Eckman, D.W. Dickson, M. Hutton, J. Hardy, T. Golde, Abeta42 is essential for parenchymal and vascular amyloid deposition in mice, Neuron, 47 (2005) 191-199.

[53] C. Lendel, M. Bjerring, A. Dubnovitsky, R.T. Kelly, A. Filippov, O.N. Antzutkin, N.C. Nielsen, T. Hard, A hexameric peptide barrel as building block of amyloid-beta protofibrils, Angew Chem Int Ed Engl, 53 (2014) 12756-12760.

[54] G. Bitan, M.D. Kirkitadze, A. Lomakin, S.S. Vollers, G.B. Benedek, D.B. Teplow, Amyloid beta -protein (Abeta) assembly: Abeta 40 and Abeta 42 oligomerize through distinct pathways, Proc Natl Acad Sci U S A, 100 (2003) 330-335.

[55] E.K. Esbjorner, F. Chan, E. Rees, M. Erdelyi, L.M. Luheshi, C.W. Bertoncini, C.F. Kaminski, C.M. Dobson, G.S. Kaminski Schierle, Direct observations of amyloid beta self-assembly in live cells provide insights into differences in the kinetics of Abeta(1-40) and Abeta(1-42) aggregation, Chemistry \& biology, 21 (2014) 732-742.

[56] A. Lord, H. Kalimo, C. Eckman, X.Q. Zhang, L. Lannfelt, L.N. Nilsson, The Arctic Alzheimer mutation facilitates early intraneuronal Abeta aggregation and senile plaque formation in transgenic mice, Neurobiol Aging, 27 (2006) 67-77.

[57] O. Philipson, P. Hammarstrom, K.P. Nilsson, E. Portelius, T. Olofsson, M. Ingelsson, B.T. Hyman, K. Blennow, L. Lannfelt, H. Kalimo, L.N. Nilsson, A highly insoluble state of Abeta similar to that of Alzheimer's disease brain is found in Arctic APP transgenic mice, Neurobiol Aging, 30 (2009) 1393-1405.

[58] J. Nunan, D.H. Small, Regulation of APP cleavage by alpha-, beta- and gamma-secretases, FEBS letters, 483 (2000) 6-10.

[59] W. Chen, E. Gamache, D.J. Rosenman, J. Xie, M.M. Lopez, Y.M. Li, C. Wang, Familial Alzheimer's mutations within APPTM increase Abeta42 production by enhancing accessibility of epsilon-cleavage site, Nat Commun, 5 (2014) 3037.

[60] S. Funamoto, M. Morishima-Kawashima, Y. Tanimura, N. Hirotani, T.C. Saido, Y. Ihara, Truncated carboxyl-terminal fragments of beta-amyloid precursor protein are processed to amyloid beta-proteins 40 and 42, Biochemistry, 43 (2004) 13532-13540.

[61] N. Matsumura, M. Takami, M. Okochi, S. Wada-Kakuda, H. Fujiwara, S. Tagami, S.

Funamoto, Y. Ihara, M. Morishima-Kawashima, gamma-Secretase associated with lipid rafts: multiple interactive pathways in the stepwise processing of beta-carboxyl-terminal fragment, $J$ Biol Chem, 289 (2014) 5109-5121.

[62] Y.M. Kuo, T.G. Beach, L.I. Sue, S. Scott, K.J. Layne, T.A. Kokjohn, W.M. Kalback, D.C. Luehrs, T.A. Vishnivetskaya, D. Abramowski, C. Sturchler-Pierrat, M. Staufenbiel, R.O. Weller, A.E. Roher, The evolution of A beta peptide burden in the APP23 transgenic mice: implications for A beta deposition in Alzheimer disease, Mol Med, 7 (2001) 609-618. 
[63] T. Kawarabayashi, L.H. Younkin, T.C. Saido, M. Shoji, K.H. Ashe, S.G. Younkin, Agedependent changes in brain, CSF, and plasma amyloid (beta) protein in the Tg2576 transgenic mouse model of Alzheimer's disease, J Neurosci, 21 (2001) 372-381.

[64] K. Yanagisawa, A. Odaka, N. Suzuki, Y. Ihara, GM1 ganglioside-bound amyloid beta-protein (A beta): a possible form of preamyloid in Alzheimer's disease, Nat Med, 1 (1995) 1062-1066.

[65] N. Yamamoto, Y. Fukata, M. Fukata, K. Yanagisawa, GM1-ganglioside-induced Abeta assembly on synaptic membranes of cultured neurons, Biochimica et biophysica acta, 1768 (2007) 1128-1137.

[66] A. Kakio, S.I. Nishimoto, K. Yanagisawa, Y. Kozutsumi, K. Matsuzaki, Cholesteroldependent formation of GM1 ganglioside-bound amyloid beta-protein, an endogenous seed for Alzheimer amyloid, The Journal of biological chemistry, 276 (2001) 24985-24990.

[67] M. Ries, M. Sastre, Mechanisms of A $\beta$ Clearance and Degradation by Glial Cells, Frontiers in Aging Neuroscience, 8 (2016) 160. 